\title{
A EDUCAÇÃO ESPECIAL NO MARANHÃO: apontamentos históricos ${ }^{1}$
}

\author{
SPECIAL EDUCATION IN MARANHÃO: historical notes
}

\section{LA EDUCACIÓN ESPECIAL EN MARANHÃO: apuntes históricos}

\author{
Mariza Borges Wall Barbosa de Carvalho \\ Professor Doutor da Universidade Federal de São Carlos (UFSCar). \\ mariwall@uol.com.br \\ Maria Núbia Barbosa Bonfim \\ Professor Doutor da Universidade Federal de São Carlos (UFSCar). \\ bonfim@elo.com.br
}

\begin{abstract}
RESUMO: Debate sobre a trajetória da Educação Especial no Estado do Maranhão, enfocando a institucionalização da área no órgão governamental responsável pela educação, das primeiras iniciativas ao ano de 2002. Apresenta análise documental realizada em registros do órgão estadual de educação: propostas, projetos, relatórios dentre outros. Acrescenta referências pontuais à educação regular visando situar o surgimento da Educação Especial no contexto da educação geral. Indica a criação de setores; os serviços oferecidos; o processo de encaminhamento e a relação público/privado. Caracteriza a Educação Especial maranhense apontando a correspondência com o desenvolvimento do quadro nacional; início do atendimento nas áreas de deficiência visual e auditiva; criação das classes especiais para a área de deficiência mental para alunos que já estavam na escola; relação com a rede privada; entrelaçamento com a área da saúde; oscilações na representação da área na estrutura do órgão governamental responsável pela educação. Finaliza com um quadro síntese da cronologia da Educação Especial maranhense.

PALAVRAS-CHAVE: história da educação especial; análise documental; educação especial maranhense
\end{abstract}

ABSTRACT: It debates about the background of special education in the state of Maranhão, focusing on institutionalization of the area in the government agency responsible for the education first started in 2002. It presents a document analysis carried out on state government records in the following areas of education: proposals, projects, reports among others. It adds specific references to regular education in order to situate the emergence of Special Education in the context of general education. Denotes the creation of sectors; services offered; process of referral and the public / private relationship. It characterizes Special Education in Maranhão pointing to correspondence with development of the national framework; beginning the service in the areas of visual and hearing disability; creation of special classes for the area of intellectual disability for students already in the school; relationship with private network; presence in the health sector; area representation fluctuations in the governmental agency structure responsible for education. It concludes with a summary table of the chronology of maranhense Special Education.

KEYWORDS: History of special education. Document analysis. Maranhense special education.

RESUMEN: En este trabajo se debate la trayectoria de la Educación Especial en la provincia de Maranhão, enfocando la institucionalización del área en el órgano gubernamental responsable por la educación, desde las primeras iniciativas hasta el año 2002. Se presenta un análisis documental realizado en registros del órgano provincial de educación: propuestas, proyectos, informes, entre otros. Se agregan referencias puntuales a la educación regular buscando situar el surgimiento de la Educación Especial en el contexto de la educación general. Se indica la creación de sectores, los servicios ofrecidos, el proceso de direccionamiento y la relación entre lo público y lo privado. Se caracteriza la Educación Especial de Maranhão señalando su correspondencia con el desarrollo del nivel nacional: comienzo del atendimiento en las áreas de deficiencia visual y auditiva; la creación de las clases especiales para el área de deficiencia mental para alumnos que ya estaban en la escuela; la relación con la red privada; su entrelazamiento con el área de salud; las oscilaciones en la representación del área en la estructura del órgano gubernamental responsable por la educación. Finaliza con un cuadro que sintetiza la cronología de la Educación Especial de Maranhão.

PALABRAS CLAVE: Historia de la educación especial. Análisis documental. Educación especial de Maranhão.

\footnotetext{
${ }^{1}$ Texto integrante da pesquisa "História da Educação Especial no Maranhão", em processo de reativação. Optamos por apresentar para discussão, neste trabalho, o período compreendido entre as origens e o inicio do século XXI.
}

Artigo recebido em setembro de 2016

Aprovado em novembro de 2016 
A EDUCAÇÃO ESPECIAL NO MARANHÃO | Mariza B. W. B. de Carvalho e Maria Núbia B. Bonfim

\section{1| INTRODUÇÃO}

A trajetória da Educação Especial no Brasil indica um desenvolvimento de serviços caracterizados, em um primeiro momento, por instituições especializadas como o Instituto dos Meninos Cegos, hoje denominado Instituto Benjamin Constant (IBC), e o Instituto dos Surdos-Mudos, hoje Instituto Nacional de Educação dos Surdos (INES) Posteriormente foram criadas classes especiais nas escolas públicas, e mais recentemente os serviços da área são predominantemente complementares ou suplementares aos serviços do ensino comum. Ademais é significativa a participação de instituições filantrópicas na Educação Especial brasileira tendo sido responsável por muito tempo por grande parte das matrículas.

A implantação e expansão dos serviços de Educação Especial no Maranhão seguiram as diretrizes políticas nacionais com a predominância da criação de classes especiais na rede pública estadual, e de um setor específico na estrutura do órgão responsável pela educação. A oficialização dos serviços dessa área no final da década de 1960 indica a tendência para a integração, perspectiva dominante nessa época que preconizava o atendimento em ambiente o menos restritivo possível, com a criação de classes especiais nas escolas comuns. Também podemos observar a participação expressiva das instituições filantrópicas na Educação Especial maranhense.

Os registros da trajetória da Educação Especial maranhense ainda são escassos, o que provocou a elaboração desse trabalho. Assim, será feita uma retrospectiva da Educação Especial no Estado do Maranhão, de suas origens ao ano de 2002, destacando-se a atuação do órgão estadual de educação. Portanto, cronologicamente se retornará aos anos 1960, quando é registrado o início do atendimento em Educação Especial.

A análise empreendida será baseada em documentos do setor estadual responsável pela Educação Especial do Maranhão. Também serão feitas referências pontuais à educação regular da época, procurando esboçar o quadro educacional maranhense, visando situar o surgimento da Educação Especial no contexto da educação geral.

\section{2| A IMPLANTAÇÃO DA EDUCAÇÃO ESPECIAL}

Na década de 60, mais precisamente em 1962, 1964, 1966 e 1969, podem-se indicar os trabaIhos iniciais em Educação Especial no Maranhão. As duas primeiras referências (62 e 64) são da iniciativa privada, uma classe para alunos deficientes mentais ${ }^{2}$ e auditivos e outra para deficientes visuais que resultou na criação da Escola de Cegos do Maranhão ${ }^{3}$ (MARANHÃO, 1991b).

Em 1966, o atendimento a alunos deficientes auditivos é iniciado no âmbito da educação pública, e em 1969 a Portaria n 423/69 criou o Projeto Plêiade de Educação de Excepcionais ${ }^{4}$, subordinado ao Departamento de Educação Primária, da Secretaria de Estado dos Negócios de Educação e Cultura, marcando o início oficial da Educação Especial da rede pública no Estado do Maranhão. Esses acontecimentos se enquadram no que Bueno (1997) denomina

\footnotetext{
${ }^{2} \mathrm{~A}$ terminologia utilizada é a constante dos documentos.

${ }^{3}$ Bueno (1993) indica, nesse ano de 1964, a criação da Escola de Cegos do Maranhão (p.95).

${ }^{4}$ Cabe esclarecer que o Governo Estadual (1966-70) adotou a sistemática de Projetos para o desenvolvimento das ações prioritárias em educação, de modo a escapar do processo lento que caracterizava essas ações. A principal característica dos projetos seria o dinamismo, mesmo gerando um desenho considerado "imediatista", de forma a marcá-los como inovadores, a partir da própria denominação relacionada com o objetivo maior de cada um. Por exemplo: Projeto Bandeirante, numa alusão às "entradas e bandeiras" do período colonial, visto que, ao partir da Capital
} 
[...] terceiro momento da educação especial [...] caracterizado pela expansão da ação do poder público, com a criação e desenvolvimento dos serviços de Educação Especial no nível de governo federal e de todos os estados da Federação, bem como pela disseminação de uma rede privada assistencial que atinge todo o país [...] (p.173).

Os traços característicos da Educação Especial brasileira, já identificados por autores como Bueno (1993), Jannuzzi (1996), Mazzotta (1996) e Ferreira (1993), estão nitidamente presentes na trajetória da Educação Especial maranhense.

No ano de 1962, o governador do Estado do Maranhão era Newton de Barros Bello (19611965). Segundo análise de Bonfim (1985), o quarto dos dirigentes apoiados por Vitorino Freire, político influente da época.

Assim sendo, o que acontecia nos períodos eleitorais era tão somente a substituição de um governador por outro que não se atreveria a aventurar-se em críticas ao seu antecessor (se é que as tivesse). Portanto, o que se pode verificar em todos os setores é um crescimento apenas esporádico ou vegetativo.

Em se tratando do plano educacional [...] as modificações havidas e inovações introduzidas decorriam das diretrizes advindas dos Projetos do Ministério de Educação e Cultura e traçadas para todo o país. (p.51).

Para dar uma ideia da situação educacional da época, em 1961 registravam-se 448.000 crianças em idade escolar e apenas 159.000 crianças estavam matriculadas (MARANHÃO apud BONFIM, 1985, p.55), o que significava 35,49\%. Em 1966, no ensino primário, eram 560.261 crianças em idade escolar e somente 244.634 crianças eram atendidas, o que correspondia a $43,66 \%$, ou seja, nem mesmo a metade da população era atendida (MARANHÃO apud BONFIM, 1985, p.70). Também, relembrando, é desse período a nossa primeira LDB (4.024/61), os acordos MEC/USAID e, em 1964, o Golpe Militar.

Em 1966, assume o governo do Estado do Maranhão José Sarney (1966-1970). No projeto para o seu governo, denominado Maranhão Novo, segundo Nascimento, "[...] a educação foi convocada, ganhou relevância social para definir a ideologia do NOVO que se instaura no Estado." (p.34, grifo do autor). Porém, os graves problemas educacionais (foco desse trabalho) persistiram. Como exemplo, podemos citar "O déficit de atendimento da população em idade escolar de $1^{\circ} \mathrm{grau}$ no Maranhão, em 1970, era de 57\% em relação ao total da população em idade escolar (de 7 a 14 anos)[...]" (ROSAR, 1995, p.123), ou ainda, segundo o Censo de 1970, o índice de analfabetismo era de 65,40 \%, "[...] não tendo baixado no decênio, mais que 6,37 por cento sobre o anterior, enquanto o médio do país, caindo para 34,11 por cento, baixara o dobro - 13,57 por cento[...]" (MEIRELES, 2001, p.386).

A Educação Especial foi oficializada em 1969, com o Projeto Plêiade, cuja finalidade era a de "[...] promover a educação de crianças, adolescentes e adultos excepcionais, assim como o aperfeiçoamento e treinamento de pessoal para o campo de ensino especial [...]" (MARANHÃO, [entre 1971 e 1977], p.2). O setor de deficientes visuais visava "Oferecer aos Deficientes Visuais condições de se desenvolverem integralmente, dentro de sua limitação, na sociedade, na família e na comunidade". (MARANHÃO, 1969).

para o Interior, o Projeto significaria iniciar/desbravar/empreender; Projeto Centauro, que preconizava a instalação e funcionamento de uma Faculdade de Formação de Professores para o $1^{\circ}$ Ciclo, com o objetivo de qualificar professores, e cujo título se refere a uma das constelações mais brilhantes do nosso firmamento. Sob essa orientação foram criados e executados outros projetos: João de Barro, Vega, Sagitário, Plêiade. Mesmo realizando cuidadosa pesquisa, até o momento, não conseguimos uma informação fidedigna sobre a escolha da denominação Plêiade para o Projeto em análise. 
Também participava do projeto a Escola de Cegos do Maranhão (ESCEMA), mantida pelo Lions Club, logo depois desligada do projeto. Sobre tal desligamento, afirmou-se que provocou problemas quanto à redução do número de alunos e na própria execução do trabalho (MARANHÃO, 1969). Não há registro, no entanto, dos motivos do desligamento da instituição. O Projeto previa recebimento de recursos da Campanha Nacional de Educação de Cegos.

Nacionalmente, as iniciativas oficiais eram as campanhas ${ }^{5}$ do final da década de 50. Em 1971 foi criado o Grupo Tarefa, no Ministério da Educação e Cultura que resultaria na fundação do Centro Nacional de Educação Especial (CENESP), em 1973. Essa área foi considerada prioritária no Plano Setorial de Educação e Cultura 1972/74. (BUENO, 1993) ${ }^{6}$.

Em 1971, o Projeto Plêiade é ampliado para atender aos deficientes mentais, mediante a abertura de classes especiais". Aqui, novamente, a "marca" da educação brasileira dos considerados deficientes mentais: a criação de classes especiais foi mais provocada por situações de dentro da escola do que pelo fato de que havia quem não estivesse nela; foram criadas para alunos que já estavam na escola e não para trazer os que não a frequentavam.

Segundo Ferreira (1993),

O Estado aumentou as oportunidades com abertura de classes especiais, principalmente para deficientes mentais, junto às escolas públicas. Essas classes que nascem e crescem para absorver as deficiências leves, já que os problemas são detectados dentro do sistema escolar. (p.32).

Alguns anos depois de sua implantação, a Educação Especial (provavelmente em 1972) apresentava o seguinte quadro: o Projeto Plêiade contava com 24 profissionais: 17 professores (7 para deficientes auditivos, 5 para deficientes mentais e 5 para deficientes visuais); 2 coordenadores (1 administrativo e 1 pedagógico); 5 supervisores (3 para a área de deficiência mental, 1 para a visual e 1 para a auditiva) e 202 alunos: 37 deficientes auditivos, 23 visuais e 142 mentais, para 19 classes (5- deficiência auditiva, 2- visual e 10- mental), ensino itinerante e ensino integrado.

Na rede particular eram 174 alunos (129 deficientes mentais e 45 deficientes visuais) em 3 instituições: Instituto São Jorge e Escola "Eney Santana”; APAE - São Luís com deficientes mentais e Escola de Cegos do Maranhão.

Mais uma característica da Educação Especial do período: a forte presença da iniciativa privada, predominantemente filantrópica. Do quantitativo de alunos citado anteriormente (202 e 174), 53, $47 \%$ eram da rede pública e $46,53 \%$ da rede privada.

É importante ressaltar-se que, nesse momento de início de Educação Especial no Estado, a rede pública que, no caso, era só a estadual, não oferecia serviços em escolas especiais. Estas, quando criadas, eram da rede privada.

Também cabe destacar que as classes especiais da rede estadual eram subordinadas às escolas

\footnotetext{
${ }^{5}$ Campanha para a Educação do Surdo Brasileiro (CESB) de 1957; Campanha Nacional de Educação dos Cegos (CNEC) de 1960 e Campanha Nacional de Educação e Reabilitação do Deficiente Mental (CADEME) de 1960 (Bueno, 1993).

${ }^{6}$ Vários autores já trataram dessa temática, por isso não será mais explorada neste trabalho. Dentre esses autores, Bueno (1993); Mazzotta (1996); Nunes e Ferreira (1994); Jannuzzi (1997).

${ }^{7}$ Esses alunos foram assim identificados nos documentos encontrados: na década de 70 "[...] com atraso pedagógico e problemas de personalidade [...]" (MARANHÃO [entre 1971 e 1977] p.2); nos anos 80 "[...]que apresentaram dificuldades pedagógicas, além de problemas psicológicos [...] alunos considerados deficientes mentais educáveis." (MARANHÃO, 1986, p.05) e na década de 90 "[...]com atraso na aprendizagem além de problemas psicológicos [...] portadores de problemas mentais. [...] vistos como educáveis[...]" (MARANHÃO, 1991b, p.1).
} 
onde funcionavam e as professoras estavam, sob o ponto de vista administrativo, ligadas ao Departamento de Educação Primária, como as demais professoras do ensino regular, e recebiam "[...] assistência e orientação técnico-pedagógica da Coordenação do Projeto, através dos supervisores". (MARANHÃO, [entre 1971 e 1977]). Esse procedimento sofre as consequências contraditórias da existência de um setor específico para Educação Especial. Se por um lado fortalece a área, por outro contribui para a segregação dessa mesma área no sistema educacional do qual faz parte.

No intervalo de 1971 a 1977, ainda existe o registro de mais uma instituição no interior do Estado: a escola Santa Terezinha-APAE, no município de Coroatá e outra no município de Pedreiras a ser instalada. Era prevista a implantação de classes especiais nos municípios de Codó, Ribamar e Pinheiro, que já possuíam professores especializados. Também havia 341 alunos, provavelmente na rede estadual:, sendo 72 deficientes auditivos; 32 deficientes visuais e 237 deficientes mentais. Quanto ao Projeto Plêiade:

[...] continuou prestigiando a iniciativa privada que se dedicava a esse campo de educação. Procurando valorizar os esforços comunitários pela educação e integração do excepcional, manteve contatos com escolas particulares e filantrópicas auxiliando-as mediante remuneração do pessoal, cedência de professores especializados, material escolar, e, principalmente oferecendo orientação técnica-pedagógica aos que solicitava. Convém ressaltar, que nesta mesma diretriz incentivou a criação da APAE (MARANHÃO,[entre 1971 e 1977], p.2).

No que se refere à relação de órgãos governamentais com o setor privado, ainda pode-se citar uma das metas do Projeto Plêiade: "[...] prover, não só o Projeto, mas também as instituições que cuidam do excepcional de maiores recursos [...]" (MARANHÃO, [entre 1971 e 1977]). Também cita-se o registro de assistência à escola da APAE (explicitamente assistência financeira) e à Escola de Cegos do Maranhão.

Nos documentos analisados não se identificou com exatidão o processo de encaminhamento para a Educação Especial. Pode-se inferir que havia uma prática de diagnóstico, pois a estrutura interna do Projeto possuía uma equipe multidisciplinar que, dentre suas funções, constava a de "[...] diagnosticar e acompanhar o tratamento dos casos" (MARANHÃO, [entre 1971 e 1977]), além de apontar como característica do ensino especial o "[...] entrosamento com outros órgãos, principalmente a Secretaria de Saúde, para efetuar uma triagem e seleção dos alunos" (MARANHÃO, [entre 1971 e 1977]).

Também trazemos para o debate a inserção da Educação Especial no Plano Estadual de Educação - Maranhão 1971-1974, em que podemos indicar as seguintes referências à área: como uma das quinze diretrizes propostas para a política educacional "[...] Propiciar especial atenção aos deficientes físicos e mentais, levando-os à realização pessoal e à adaptação ao convívio social, estabelecendo, aos superdotados, incentivos que lhes possibilitem desenvolver ao máximo suas potencialidades" (MARANHÃO, [entre 1970 e 1971], p.25). Registramos aqui, a ausência de referência à Educação Especial nas estratégias.

Um dos objetivos contempla a área "Levar os alunos excepcionais a se desenvolverem de acordo com a sua capacidade" (MARANHÃO, [entre 1970 e 1971], p.28). Ainda encontramos o registro de uma das metas e prioridades "Elevar em 100\% a matrícula das classes de excepcionais de responsabilidade direta ou indireta do Estado" (MARANHÃO, [entre 1970 e 1971], p.31, grifo nosso). Observamos o aspecto positivo de estipular uma previsão quantitativa de aumento de matrículas (100\%), destacamos também a responsabilidade indireta apontada.

Esse documento contém cinco subprogramas, a saber: 1- reforma e integração do sistema educacional do Estado; 2- implantação do ensino de $1^{\circ}$ e $2^{\circ}$ Graus; 3- incremento ao ensino supletivo; 
A EDUCAÇÃO ESPECIAL NO MARANHÃO | Mariza B. W. B. de Carvalho e Maria Núbia B. Bonfim

4- integração da rede estadual de ensino superior e 5- incentivo às atividades desportivas. Encontramos a Educação Especial em dois deles, no subprograma implantação do ensino de $1^{\circ} \mathrm{e}$ $2^{\circ}$ Graus e no de incentivo às atividades desportivas.

No que se refere à implantação do ensino de $1^{\circ}$ e $2^{\circ}$ Graus, um dos objetivos propostos para o quadriênio 1971-74, é o de "Incrementar em 100\% a matrícula das classes de excepcionais mantidas ou subvencionadas pelo Estado" (MARANHÃO, [entre 1970 e 1971], p.42, grifo nosso). Já o de incentivo às atividades desportivas considera como objetivo "Organizar nas escolas o desporto educativo às aptidões dos alunos e promover o atendimento aos deficientes de qualquer natureza" (MARANHÃO, [entre 1970 e 1971], p.66).

Desses documentos da década de 70 é interessante salientar alguns trechos: Os alunos considerados como deficientes mentais das classes especiais públicas eram identificados como limítrofes ou educáveis e os das instituições particulares como treináveis, educáveis e semidependentes (MARANHÃO, [1972?]) ${ }^{8}$. O atendimento era educativo, escolar, assistencial, social e mais amplamente por uma integração:

[...] temos feito algo que nos reanima no trabalho tais como: [...] maior integração e adaptação social do excepcional na escola-família-comunidade, sobretudo, engajamento do excepcional no campo do ensino comum." (MARANHÃO, [entre 1971 e 1977]).

Ou então como uma das metas do Projeto Plêiade: "[...] a fim de oferecer não apenas a educação, mas a integração social do aluno"; (MARANHÃO, [entre 1971 e 1977]).

Embora mencione a política educacional

[...] assistência técnica dos órgãos federais no que concerne a orientações sobre as novas diretrizes preconizadas pela política educacional do país a respeito da educação do excepcional. (MARANHÃO, [1972?]).

Em 1977, os serviços de Educação Especial são ampliados para o interior do Estado em quatro municípios (MARANHÃO, 1991b). Não foi possível identificar quais e nem o número de alunos. Talvez os citados (Codó, Ribamar e Pinheiro) pela informação da existência de professores especializados e também porque já havia sido mencionada a previsão de expansão para esses municípios. Em 1978, o Projeto Plêiade é substituído pela Seção de Educação Especial pelo Decreto 6.838/78, com a finalidade de "promover o atendimento educativo ao deficiente proporcionando-Ihe sua integração social” (MARANHÃO, 1991b, p.1), subordinada à Coordenação de Ensino de $1^{\circ} \mathrm{grau}$.

Em relação à educação de uma forma geral, o Maranhão é um dos Estados brasileiros, cujo processo de municipalização do ensino fundamental já se anuncia desde a década de 1970, participando de projetos provenientes de acordos MEC/BIRD, quer específicos para o então $1^{\circ} \mathrm{grau}$, como o Promunicípio (1975) e o Edurural (1980), quer daqueles destinados ao desenvolvimento da região e que contemplavam a educação, como o Polonordeste (1977) e o Poloamazônia (1974) (ROSAR e SOUSA, 1999). Esses projetos,

[...] apresentavam como metas a universalização do acesso ao ensino fundamental, a redução da taxa de analfabetismo, o aumento da produtividade da escola, a melhoria da qualidade do ensino, a valorização do magistério, contemplando em suas ações a construção e reformas de prédios escolares, a estruturação dos órgãos municipais de educação, a capacitação de professores e organização curricular. Findo os projetos, entretanto, a situação do sistema educacional permanecia inalterada [...]. Sousa e Abreu (1999, p.2)

${ }^{8}$ Em 1986, constava a denominação educáveis. 
Ainda que já venha ocorrendo todo esse processo de municipalização, o entrosamento Estado/ Município permanece restrito à transferência de recursos financeiros. A necessidade de maior integração entre os dois sistemas é apontada inclusive pelo então dirigente do órgão estadual de educação (ROCHA, 1999).

A Educação Especial maranhense, entretanto, surgiu no âmbito estadual, permanecendo, até o período destacado para este estudo, a rede de ensino que concentrou o maior número de matrículas ${ }^{9}$.

\section{3| A EXPANSÃO DOS SERVIÇOS EM EDUCAÇÃO ESPECIAL}

Em 1980, é iniciado o Programa de Bolsa de Trabalho pelo convênio entre o MEC/CENESP e a Secretaria de Educação, "[...] visando o engajamento do aluno excepcional no mercado de trabalho". (MARANHÃO, 1991b, p.5)

Em 1982, é criado, na rede estadual, o Centro de Ensino Especial "Helena Antipoff", para atender aos alunos do ensino especial maiores de 14 anos, com um trabalho dirigido para a profissionalização (MARANHÃO, 1986) ou pré-profissionalização (MARANHÃO, 1991). Nesse período, nos anos 80 , havia o seguinte contingente de alunos:

TABELA 1. Matrículas Educação Especial por rede de ensino Maranhão 1981, 1987 e 1988

\begin{tabular}{cccccc}
\hline Ano & Total & Federal & Estadual & Municipal & Privada \\
\hline 1981 & 962 & - & 519 & - & 443 \\
1987 & 1.811 & - & 1.055 & 31 & 725 \\
1988 & 1.809 & - & 1.207 & 106 & 496 \\
\hline
\end{tabular}

Fonte: MEC/SG/SEPLAN/ SEEC 1985,1991 e 1990.

Nota: os informes estatísticos nacionais da Educação Especial na década de 80 não eram regulares.

No ano de 1981, as redes estadual e particular praticamente dividiam o atendimento em Educação Especial. A rede estadual assumiu o maior número de alunos no ano de 1988. Para dar uma noção do Ensino de $1^{\circ}$ grau, no ano de 1985, estavam matriculados 818.816 alunos (NASClMENTO, 1995).

Em 1984, pelo Decreto n`186, na reforma administrativa da Secretaria de Educação, a Seção de Educação Especial é transformada em Centro de Educação Especial, subordinado diretamente à Superintendência de Ensino da Secretaria de Educação. O quadro de profissionais era composto por técnicos, psicólogos, assistentes sociais, médicos, supervisores e orientadores educacionais. Os professores das classes especiais continuavam ligados às escolas as quais pertenciam suas classes e, portanto, à Coordenação de Ensino de $1^{\circ} \mathrm{grau}$. Financeiramente, o Centro recebia recursos do CENESP/MEC e da Quota Estadual.

As áreas de deficiência atendidas continuavam a ser auditiva, mental e visual, na capital e no interior, no pré-escolar, $1^{\circ}$ e $2^{\circ}$ graus. $O$ currículo utilizado nas classes especiais era o proposto pelo CENESP/MEC.

Em 1985, foram criadas classes para alunos de aprendizagem lenta, tendo em vista que "[...] os resultados do diagnóstico realizado por este setor junto às classes regulares [...] retrataram um número significativo de alunos com dificuldade de aprendizagem [...]" (MARANHÃO, 1986, p.8).

\footnotetext{
${ }^{9} \mathrm{Em}$ 2002, das 6.703 matrículas em Educação Especial, 2.796 eram da rede estadual, representando 47,7\% do total de matrículas.
} 
A previsão para o tempo de permanência dos alunos era de 2 anos nessas classes; no final desse período o aluno era encaminhado para o ensino regular ou para a classe especial. No currículo, "[...] levou-se em conta a proposta de ensino de $1^{\circ} \mathrm{Grau}$ regular do Estado, realizando-se uma dosagem em termos de conteúdos mínimos" (MARANHÃO, 1986, p.8). Essas classes funcionaram até os anos iniciais da década de 90 e seus alunos, ao fechamento delas, após análise da equipe, tiveram as duas opções citadas.

Da mesma forma que da implantação de classes especiais, a classe para alunos de aprendizagem lenta iniciou na capital para depois atingir o interior no ano seguinte. Na capital, iniciou com duas classes e 46 alunos; no interior, com duas classes.

O procedimento para ingressar na Educação Especial começava com uma avaliação pela equipe de triagem que, após o estudo de caso, dirigia o resultado para o Centro de Educação Especial, com um diagnóstico entregue à equipe responsável pela supervisão, pessoal encarregado de levá-lo até a professora de classe especial. Para a família, o encaminhamento à classe especial, se fosse esse o resultado, era dado no Centro de Educação Especial, sendo o aluno encaminhado a uma escola mais próxima de sua casa que tivesse classe especial ${ }^{10}$.

Havia uma recomendação de não se aceitar alunos na classe especial que não tivessem sido avaliados. Por um lado, esse procedimento dificultava ou mesmo evitava encaminhamentos pela própria escola, considerados inadequados, se é que se podem considerar adequados todos os que eram feitos pela equipe de triagem. Por outro, de certa maneira, atrapalhava o acesso mais amplo.

Para a "saída" da Educação Especial, o aluno também era avaliado, ou melhor, reavaliado pela equipe de triagem, sendo dessa equipe a decisão de ida, ou retorno, para o ensino regular, fase chamada de reintegração. Por vezes, esse processo era questionado pelas professoras e supervisoras de classes especiais, quando havia desacordo entre a avaliação da equipe de triagem e a das classes especiais, principalmente na área de deficiência mental11.

Desse processo de diagnóstico também é interessante registrar que, em alguns anos, houve, além da triagem realizada com alunos vindos da comunidade, isto é, encaminhados pelos familiares ou por profissionais, outra em que a equipe se deslocava até as escolas para avaliar os alunos indicados pelas suas professoras e equipe da escola a que pertenciam, que apresentavam suspeita, características de excepcionalidade. Nesses casos, pedia-se um relatório da professora sobre o porquê da indicação ${ }^{12}$.

O resultado da triagem, com o possível encaminhamento para a classe especial, era comunicado à escola e aos responsáveis pelas supervisoras. Caberia à família o direito de não aceitar a ida para a classe especial e o aluno podia permanecer na classe regular. Nesse caso, o responsável pelo aluno precisava assinar um termo de compromisso e a escola devia aceitar a decisão.

O resultado da triagem, com o possível encaminhamento para a classe especial, era comunicado à escola e aos responsáveis pelas supervisoras. Caberia à família o direito de não aceitar

\footnotetext{
${ }^{10}$ Durante algum tempo, a maioria das classes especiais para deficientes auditivos e visuais concentrava-se em uma única escola na capital. Por volta de 92/93, a escola que tinha as classes especiais para deficientes auditivos não lhes disponibilizou mais salas, levando a uma certa desacomodação para os alunos, familiares e ocasionando a transferência das classes para outras escolas. Acabaram por concentrar-se novamente numa outra escola.

11 Já na década de 90, a "saída" foi modificada, ficando a decisão ao encargo das supervisoras e das próprias professoras das classes especiais de encaminhar o aluno para o ensino regular ou ao CEE Helena Antipoff, quando atingia 14 anos (esse limite de idade tinha certa flexibilidade), se não apresentasse as condições esperadas para o ensino regular.

${ }^{12}$ Houve ocasião, no final dos anos 80 de uma escola ter uma lista de quase 50 alunos e desses, aproximadamente, apenas 10 tiveram como resultado a orientação para a classe especial.
} 
A EDUCAÇÃO ESPECIAL NO MARANHÃO | Mariza B. W. B. de Carvalho e Maria Núbia B. Bonfim

a ida para a classe especial e o aluno podia permanecer na classe regular. Nesse caso, o responsável pelo aluno precisava assinar um termo de compromisso e a escola devia aceitar a decisão.

Nesse período dos anos 80, constava nos diagnósticos a denominação de deficientes mentais educáveis ou treináveis e indicações às vezes difíceis de serem atendidas como terapia, fonoaudiologia. Depois se passou a indicar a classe especial, sem especificar educável ou treinável. As classes especiais eram distribuídas conforme as áreas de deficiência.

Ainda havia na equipe do Centro de Ensino Especial neuropediatra, pediatra, otorrino, oftalmologista e cardiologista. Fato considerado, assim, nos dois documentos analisados que os citam: "Torna-se oportuno salientar, a assistência médica sistemática a todos os alunos de classes especiais, encaminhados pelo Centro de Educação Especial [...]" (MARANHÃO, 1986, p.5).

Isso demonstra uma das distorções apontadas por Bueno (1993):

É certo que grande parte das crianças excepcionais apresenta dificuldades das mais variadas ordens, decorrentes de sua excepcionalidade, que exigem atendimentos específicos os quais devem ser, portanto, considerados dentro dos direitos da cidadania. Esses atendimentos, porém, se situam na área da saúde [...] (p.20).

Mas, a

[...] baixa qualidade dos serviços de saúde oferecidos à maior parte da população: na medida em que cuidados muito mais rudimentares que os necessários para a criança excepcional não são oferecidos à população em geral, a Educação Especial passa a abarcá-los como se fossem de sua alçada [...] (p.20).

Jannuzzi (1997a) aborda essa relação educação / saúde na Educação Especial, apontando as ambiguidades nas aplicações de verbas, formação de professores e no currículo escolar. A autora recorre à legislação para chamar atenção sobre o caráter de complementaridade entre educação e saúde existente na Constituição.

As modalidades de atendimento continuavam a ser: classe especial, ensino itinerante (para deficientes auditivos e visuais), oficina pedagógica (para deficientes auditivos e mentais), sala de recurso (para deficientes auditivos) e bolsa de trabalho.

Outro ponto importante diz respeito à expansão da Educação Especial em que

[...] vale ressaltar o Plano Diretor para o quadriênio 83/86, que preconiza o aumento da população escolar nesse nível [...] o trabalho referente à chamada escolar, nestes anos, vem contribuindo para a consecução do objetivo previsto, uma vez que, considerando uma matrícula de 576 alunos em 1982, hoje, encontram-se matriculados 860 alunos, capital e interior, incluindo pré-escolar, $1^{\circ}$ e $2^{\circ}$ graus[...] (MARANHÃO, 1986, p.07).

O que efetivamente mostra um aumento de $49,3 \%$ de matrículas no ensino especial. Foi suficiente?

Em 1991, a Educação Especial pelo Decreto n 11.858, passou a ser responsabilidade da Divisão de Educação Especial que, junto com a Divisão de Ensino Supletivo, eram subordinadas à Coordenadoria Especial de Ensino.

A vinculação com a educação supletiva parece ter sido decorrente da própria reestruturação do órgão nacional, como é assinalado pela SEESP, no documento Educação Para Todos (BRASIL, 2000), quando a Secretaria de Educação Especial- SESP, em 1990, passou a fazer parte da Secretaria Nacional de Educação Básica, como Departamento de Educação Supletiva e Especial- 
A EDUCAÇÃO ESPECIAL NO MARANHÃO | Mariza B. W. B. de Carvalho e Maria Núbia B. Bonfim

\section{DESE (JANNUZZI, 1996) $)^{13}$.}

Em 1993, a Secretaria Municipal de Educação de São Luís-SEMED, por meio de convênio entre essa prefeitura e o MEC/FNDE, iniciou o trabalho na área da Educação Especial sob a responsabilidade do Núcleo de Educação Especial ligado ao Departamento de Educação da SEMED. No ano seguinte, deu-se a instalação dos serviços de sala de apoio pedagógico específico para alunos com dificuldades de aprendizagem que continuavam no ensino regular e frequentavam a sala de recurso em turno inverso. Instalou-se, também, o ensino fundamental sem seriação para alunos com deficiência mental. No último caso, segundo as informações obtidas, eram alunos já diagnosticados. (SÃO LUÍS, 2002a). ${ }^{14}$

Santos (2001) destaca o processo de avaliação psicopedagógica dos alunos com dificuldades de aprendizagem que ocorria na sala de recursos, em situação de aprendizagem. Professores e técnicos especializados acompanhavam os alunos e

Após o esgotamento dos métodos e recursos utilizados e o aluno não apresentar um rendimento satisfatório na aprendizagem, o mesmo é submetido a um diagnóstico diferencial realizado pela equipe técnica interdisciplinar composta por profissionais da área de pedagogia, psicologia e serviço social, para estudo de caso e proceder aos encaminhamentos adequados. (p.45-46).

Em 1995, na Secretaria de Estado da Educação, pelo Decreto no 14.422, de 07 de fevereiro de 1995, a Divisão de Educação Especial passa a denominar-se Divisão de Ensino Especial ainda com o Ensino Supletivo e permanece subordinada à Coordenadoria Especial de Ensino que passa a chamar-se Coordenadoria de Ensino Especial.

É importante registrar que, entre 1995 e 1996, embora já houvesse a "reintegração", foi implantado o Projeto Integração Escolar do aluno portador de deficiência mental, com o subprojeto Sala de Recursos, o qual trouxe mudanças no processo de ida, ou regresso, para o ensino regular e mesmo ingresso no ensino especial. Também são implementados os projetos de supletivo especial e a proposta de integração de alunos portadores de deficiência mental de 4 a 6 anos, nos jardins de infância da rede regular, acabando com as classes especiais nesse nível de ensino.

Na década de 90, é possível trazer o seguinte quadro do ensino regular: em 1995, o Maranhão foi o Estado de pior desempenho nacional no Sistema de Avaliação da Educação Básica - SAEB, com uma média de acertos de 57,3\%. Em 1997, conseguiu ultrapassar Amapá, Roraima e Acre, ficando em $24^{\circ}$ lugar, com $55,7 \%$ e mais próximo da média nacional de 59\% (ROCHA, 1999). Apesar de ter subido na classificação, o índice de acertos permaneceu baixo. Em 1997 ainda existiam $30 \%$ de professores leigos de $1^{\mathrm{a}}$ à $4^{\mathrm{a}}$ série; de $5^{\mathrm{a}}$ à $8^{\mathrm{a}}$ série, o percentual de não habilitados era de $80 \%$. Mais ainda "[...] de cada 100 crianças que ingressaram no Sistema Educacional Maranhense, em 1990, apenas 11 conseguiram alcançar a $8^{\mathrm{a}}$ série em 1997". (RAPOSO, 2000, p.20).

\footnotetext{
${ }^{13}$ Em nível nacional, já em 1992, retorna a uma Secretaria na estrutura básica do MEC. No Maranhão, entretanto, permaneceu até 1998.

${ }^{14}$ Segundo dados recolhidos na SEMED, o atendimento em Educação Especial foi ampliado e em 2002 apresentava as seguintes modalidades de atendimento: classe comum (inclusão); classe especial; sala de recurso; oficina pedagógica e atendimento a domicílio para uma população-alvo de educandos: cegos; com visão reduzida; surdos; com déficit auditivo; portador de condutas típicas; com deficiência física; com deficiência mental; com múltiplas deficiências e com altas habilidades (SÃO LUíS, 2002b). Também em 2002, com a Lei 4.125, a Educação Especial é de responsabilidade da Superintendência da Área de Educação Especial subordinada à Secretaria Adjunta de Ensino, da qual fazem parte as Superintendências das Áreas de: Ensino Fundamental; Educação Infantil; Jovens e Adultos; Apoio ao Educando e a Coordenação de Informação e Estatística Educacional.
} 
No Ensino Fundamental, em 1997, tinha-se uma taxa de aprovação de $69,5 \%$, ou seja, abaixo da média nacional que era de $77,7 \%$ e, acima, em relação à taxa de reprovação $-14,5 \%$ (média nacional de 11,5\%) e abandono-16,0 \% (média nacional de 10,8\%). Regionalmente, manteve certa simetria com o Nordeste: aprovação de 68,2\%; reprovação 15,5\% e abandono $16,2 \%$.

O Maranhão apresentou, em 1998, uma taxa de escolarização líquida de $88 \%$, abaixo da média regional (90\%) e da nacional (95,3\%). Nesse mesmo ano, uma taxa de distorção idade/ série de $65,3 \%$, permanecendo como no caso anterior, acima da média nacional $(46,6 \%)$ e com certa simetria regionalmente $(64,2 \%)$.

O custo/aluno da rede municipal antes do FUNDEF era de $\mathrm{R} \$ 101,00$ (o menor do Brasil), após o FUNDEF, no ano de 2000, passou para R\$315,00.

Diante do que foi apresentado, pode-se constatar a gama de problemas que povoavam a educação maranhense e, dentre as iniciativas para enfrentá-los, podem ser mencionadas as abaixo relacionadas, advindas do próprio sistema educacional maranhense e do MEC, implementadas conjuntamente.

[...] aceleração de estudos; avanço escolar; biblioteca escolar; caixa escolar; colegiados escolares; central de vagas; Farol da educação; gestão escolar; merenda escolar; gestão da qualidade total; Plano de Ação Integrada- Estado/Município; Pró-Ciência; Programa do Livro Didático; Programa Nacional de Atenção Integral à Criança; Projeto Escola Nova/ Ativa; repasses escolares; revitalização do magistério; SOS legalização de escolas; novas tecnologias; vídeo-escola (RAPOSO, 2000, p.13).

\section{O Plano Estadual de Educação 96-98 traz duas referências à Educação Especial:}

[...] num dos eixos norteadores da proposta, o aluno cidadão, ao se referir aos que se encontram à margem do processo educativo e da necessidade de maior acesso ao processo educativo juntamente com jovens e adultos trabalhadores e outros grupos. Nesse momento, fala-se explicitamente de portadores de necessidades especiais. O outro momento é na linha programática de qualidade do ensino, em que se afirmou como objetivo possibilitar o desenvolvimento de atividades curriculares para enriquecimento dos alunos superdotados. (CARVALHO, 2004, p.93).

Sob o ponto de vista da legislação educacional, em abril de 1997, foi aprovada a Resolução $177 / 97$ do Conselho Estadual de Educação -CEE/MA que estabelece normas para Educação Especial no Sistema de Ensino ${ }^{15}$.

Ainda em 1997, na rede estadual, é inaugurado o Centro Integrado de Educação Especial-C.I.E.E. Padre João Mohana. Caracteriza-se como uma das modalidades de atendimento previstas na Política Nacional de Educação Especial, com atendimentos na área de avaliação diagnóstica, estimulação precoce e escolarização.

Em 1998, na esfera estadual, com mais uma reforma administrativa, a Divisão de Educação Especial foi transformada em Assessoria de Ensino Especial e de Jovens e Adultos ligada à Supervisão de Ensino Fundamental da Gerência de Desenvolvimento Humano.

Em 1999, o C.I.E.E. Padre João Mohana iniciou o atendimento ao aluno portador de autismo infantil e o projeto de estimulação precoce para crianças de 0 a 3 anos.

15 Em 2002, é aprovada a Resolução 292 do CEE-MA que estabelece normas para a Educação Especial na Educação Básica no Sistema de Ensino. 
A EDUCAÇÃO ESPECIAL NO MARANHÃO | Mariza B. W. B. de Carvalho e Maria Núbia B. Bonfim

\title{
4 | O INICIO DO SÉCULO XXI
}

\author{
Em 2000 a rede estadual inaugura o Centro de Apoio Pedagógico-CAP, com o
}

[...] propósito de atuar como centro de referência, oferecendo serviços de apoio pedagógico e complementação didática, visando proporcionar condições que favoreçam a integração do Deficiente Visual na sociedade, permitindo igualdade e oportunidade na vida em comunidade. (MARANHÃO [entre 2001 e 2002])

É possível perceber as tendências da Educação Especial, nas diferentes épocas pelos documentos. O conjunto dos relatos da década de 70 para os outros apresenta diferenças em alguns aspectos, e em outros não. A presença do conflito, quanto aos objetivos da Educação Especial, é menos frequente, embora ainda exista: "[...] o propósito maior da Educação Especial que é o de integrar o excepcional na sociedade" (MARANHÃO, 86, p.08) ou na finalidade da Seção de Educação Especial "[...] promover o atendimento educativo ao deficiente proporcionando-lhe sua integração social” (MARANHÃO, 1991, p.1).

Já os de meados da década de 90, talvez por serem pós-LDB, são mais na perspectiva escolar, embora apareça mais a integração/inclusão que a apropriação do saber, conforme "[...] o grande desafio da Educação Especial, na esfera Pública Estadual, é a consolidação da integração escolar e profissional do nosso alunado [...]." (MARANHÃO, 1999, grifo do autor).

O exame da evolução da Educação Especial, em relação à sua representação na estrutura do órgão estadual de educação, identifica que a situação nacional foi reproduzida, porém em maior proporção, na esfera estadual.

Essas oscilações, a nosso ver, traduzem não só o poder político na área, mas também a posição ambígua de como e Educação Especial deve ser conduzida: dentro do ensino geral de $1^{\circ}, 2^{\circ}$ e $3^{\circ}$ graus, ou como um ramo com especificidades que transcendem tal circunscrição. (JANNUZZI, 1997b, p.194).

Além dessa discussão específica na área da educação, principalmente a escolar, podem-se acrescentar outras mais gerais relacionadas às pessoas que apresentam deficiências. Ao longo desses anos (da década de 60 a 2002), outras instituições com atuação relacionada às pessoas com deficiência foram surgindo no Estado.

Em 1997, foi criado o Fórum de Entidades das Pessoas Portadoras de Deficiência ${ }^{16}$ visando "[...] trabalhar de maneira unida e consciente a cidadania da pessoa portadora de deficiência física, auditiva, mental e visual em busca de um objetivo maior: CIDADANIA" (INFORUM, 2000, grifo do autor). Em 1999, o Fórum incluiu as entidades de pessoas portadoras de patologia e passou a denominar-se Fórum de Pessoas Portadoras de Deficiências e Patologias.

A seguir, apresenta-se um quadro com os principais fatos relacionados à constituição dos serviços da Educação Especial do Maranhão.

\footnotetext{
${ }^{16}$ Algumas das entidades ligadas ao Fórum: Associação dos Surdos do Maranhão (ASM), Associação dos Usuários de Psiquiatria do Maranhão (ASSUSPEMA), Associação Maranhense do Diabético Tipo I (AMADI), Associação dos Deficientes Visuais do Maranhão(ASDEVIMA), Associação dos Deficientes Físicos de São João dos Patos, Associação dos Diabéticos do Maranhão (ADIMA), Associação do Lesado Medular (ALM), Associação dos Trabalhadores Deficientes Físicos do Maranhão (ATDFEM), Associação dos Ostomizados (AOM), Centro de Assistência Profissional ao Amputado (CENAPA), Centro de Vida Independente do Maranhão (CVI), Centro Dialético de Pais e Amigos dos Especiais (CDPAE), Movimento de Reintegração do Hanseniano do Maranhão (MORHAN), Movimento PróAssociação Síndrome de Down, Programa Fala Especial - Rádio Educadora, Programa Conquista Especial - FM.
} 
A EDUCAÇÃO ESPECIAL NO MARANHÃO | Mariza B. W. B. de Carvalho e Maria Núbia B. Bonfim

\section{QUADRO 1}

\begin{tabular}{|c|c|}
\hline ANO & ACONTECIMENTO \\
\hline 1962 & Classe experimental em escola particular - deficiente mental e surdo \\
\hline 1964 & Iniciativa privada - classe para deficientes visuais - subsídio para Escola de Cegos \\
\hline 1966 & Início na rede pública com uma classe para surdos \\
\hline 1969 & $\begin{array}{l}\text { Projeto Plêiade - oficialização - Portaria } 423 / 69 \text { - subordinado ao Departamento de } \\
\text { Educação Primária }\end{array}$ \\
\hline 1971 & Expansão do Projeto Plêiade para área de deficiência mental \\
\hline 1977 & Expansão para o interior em 4 municípios \\
\hline 1978 & $\begin{array}{l}\text { Seção de Educação Especial pelo Decreto 6.838/78- subordinado à Coordenação de } \\
\text { Ensino de } 1^{\circ} \mathrm{grau}\end{array}$ \\
\hline 1980 & Programa Bolsa de Trabalho - convênio MEC/CENESP/SE \\
\hline 1982 & Criação na rede estadual do CEE Helena Antipoff \\
\hline 1984 & $\begin{array}{l}\text { Centro de Educação Especial pelo Decreto 186/84- vinculado à Superintendência de } \\
\text { Ensino da Secretaria de Educação do Estado }\end{array}$ \\
\hline 1985 & Projeto para alunos de aprendizagem lenta \\
\hline [entre 91- 92?] & Extinção das classes de aprendizagem lenta \\
\hline 1991 & $\begin{array}{l}\text { Divisão de Educação Especial pelo Decreto n } 12.035 \text {, com a Divisão de Ensino Suple- } \\
\text { tivo } \\
\text { subordinada à Coordenadoria Especial de Ensino }\end{array}$ \\
\hline 1993 & $\begin{array}{l}\text { Início dos trabalhos da Secretaria Municipal de Educação de São Luís em Educação } \\
\text { Especial }\end{array}$ \\
\hline 1994 & $\begin{array}{l}\text { Instalação, na rede municipal de São Luís, das salas de recursos e Ensino Fundamen- } \\
\text { tal sem seriação para alunos com deficiência mental e dificuldades de aprendizagem }\end{array}$ \\
\hline 1995 & $\begin{array}{l}\text { Divisão de Ensino Especial com a Divisão de Ensino Supletivo subordinada à Coorde- } \\
\text { nadoria de Ensino Especial pelo Decreto } n^{\circ} 14.422 / 95\end{array}$ \\
\hline $\begin{array}{c}\text { entre } 1995 \text { e } \\
1996 ?]\end{array}$ & $\begin{array}{l}\text { Projeto integração escolar do aluno portador de deficiência mental; } \\
\text { Subprojeto sala de recursos para alunos portadores de deficiência mental; } \\
\text { Projeto supletivo especial } \\
\text { Proposta de integração de alunos portadores de deficiência mental de } 4 \text { a } 6 \text { anos, nos } \\
\text { jardins de infância da rede regular de ensino }\end{array}$ \\
\hline 1997 & $\begin{array}{l}\text { Inauguração na rede estadual do Centro Integrado de Educação Especial Padre João } \\
\text { Mohana. }\end{array}$ \\
\hline 1999 & $\begin{array}{l}\text { Assessoria de Ensino Especial vinculada à Subgerência de Ensino subordinada à } \\
\text { Gerência de Desenvolvimento Humano. } \\
\text { Atendimento ao aluno portador de autismo infantil } \\
\text { Projeto de estimulação precoce para crianças de } 0 \text { a } 3 \text { anos. }\end{array}$ \\
\hline 2000 & $\begin{array}{l}\text { Inauguração na rede estadual do Centro de Apoio Pedagógico (CAP) Profa. Anna } \\
\text { Maria Patello Saldanha }\end{array}$ \\
\hline
\end{tabular}


A EDUCAÇÃO ESPECIAL NO MARANHÃO | Mariza B. W. B. de Carvalho e Maria Núbia B. Bonfim

Os dados obtidos indicam: início do atendimento nas áreas de deficiência visual e auditiva; criação das classes especiais para a área de deficiência mental para alunos que já estavam na escola; relação com a rede privada; entrelaçamento com a área da saúde; oscilações na representação da área na estrutura do órgão governamental responsável pela educação. Assim, esses dados sinalizam a reprodução, em nível estadual, da situação nacional da Educação Especial. 


\section{Referências}

BONFIM, M.N.B. Do velho ao novo. Política e Educação no Maranhão. São Luís: Edufma/Secret.Educ, 1985.

BRASIL. MEC. Sinopse Estatística da Educação Especial - 1981. Brasília, 1985.

MEC. Secretaria Geral. Secretaria de Articulação e Estudos de Planejamento. Serviço de Estatística da Educação e Cultura. Sinopse Estatística da Educação Especial - 1987. vols. 1 e 2. Brasília: SEEC, 1990.

MEC. Secretaria de Administração Geral. Coordenação Geral de Planejamento Setorial. Coordenação de Informações para o Planejamento. Sinopse Estatística da Educação Especial - 1988. vols. 1 e 2. Brasília: MEC/CIP, 1991.

MEC. Educação Para Todos - EFA 2000.

Avaliação: Políticas e Programas Governamentais em Educação Especial, 2000. Disponível em <http://www. mec. gov.br/seesp/publicacoes.shtm>. Acesso em 13 de março de 2002.

BUENO, J. G. S. Educação Especial Brasileira. Integração/Segregação do Aluno Diferente. São Paulo: EDUC, 1993.

Práticas institucionais e exclusão social da pessoa deficiente. IN: Educação Especial em Debate. São Paulo: Casa do Psicólogo: Conselho Regional de Psicologia, 1997. p.37-54.

CARVALHO, M.B.W.B. de. A Política Estadual Maranhense de Educação Especial (1997-2002). 2004. Tese (Doutorado em Educação) - Universidade Metodista de Piracicaba, Piracicaba, SP, 2004.

FERREIRA, J.R. A exclusão da diferença: a educação do portador de deficiência. Piracicaba: UNIMEP, 1993.

INFORUM. Informativo do Fórum de Pessoas Portadoras de Deficiências e Patologias. Ano I n I. São LuísMa, 2000.

JANNUZZI, G.M. Política Estatal Oscilante de Educação Especial e a Produção de Conhecimento. V Seminário Brasileiro de Pesquisa em Educação Especial. Universidade Federal Fluminense. Niterói- RJ, 1996.

As políticas e os espaços para a criança excepcional. IN:FREITAS, M. C. de (org.). História Social da Infância no Brasil. São Paulo: Cortez Editora, 1997a. p.183-223.

Educação, escolarização e inclusão. Sociedade Brasileira de Psicologia, 1997b. (versão preliminar).
MARANHÃO. Secretaria de Estado dos Negócios de Educação e Cultura. Projeto Plêiade. Educação de Excepcionais. Setor de Deficientes Visuais, São Luís, 1969.

Plano Estadual de Educação. Maranhão. 1971-1974 [entre 1970 e 1971].

O ensino especial no Estado do Maranhão. São Luís, [entre 1971 e 1977].

Informações sobre a Educação Especial no Estado do Maranhão. São Luís, [1972?].

Superintendência de Ensino. Centro de Educação Especial. A Educação Especial no Estado do Maranhão, São Luís-MA, 1986.

Superintendência de Ensino. Centro de Educação Especial. A Educação Especial no Estado do Maranhão, São Luis, 1991.

Assessoria de Educação Especial. São Luís, [entre 1998 e 1999].

Gerência de Desenvolvimento Humano. Supervisão de Ensino Fundamental. Assessoria de Ensino Especial e de Jovens e Adultos. Relatório da situação atual da educação especial no Maranhão - 1999, São Luís, 1999.

Gerência de Desenvolvimento Humano. Gerência Adjunta para Educação. Subgerência de Ensino. Assessoria de Ensino Especial. Diagnóstico da Educação Especial. São Luís, [entre 2001 e 2002].

MAZZOTTA, M. J.S. Educação Especial no Brasil. História e Políticas Públicas. São Paulo: Cortez, 1996.

MEIRELES, M. M. História do Maranhão. SP: Siciliano, 2001.

NASCIMENTO, I. V. do. Política educacional no Maranhão nos anos 80: ensino público de $1^{\circ} \mathrm{grau}$. Tese de doutoramento. Universidade de São Paulo. Faculdade de Educação. São Paulo, 1995.

NUNES, L. R. O. de P. e FERREIRA, J. R. Deficiência Mental: o que as pesquisas brasileiras têm revelado. IN: ALENCAR, E. M. L. S. da (org.). Tendências e Desafios da Educação Especial. Brasília: SEESP, 1994. p.50-81.

RAPOSO, C.A. A Realidade educacional maranhense: Subsídios para Reflexão. Cadernos de Pesquisa. V.2, no.1. São Luís: Mestrado em Educação/Universidade Federal do Maranhão, 2000. p.11-36 
A EDUCAÇÃO ESPECIAL NO MARANHÃO | Mariza B. W. B. de Carvalho e Maria Núbia B. Bonfim

ROCHA, R.M.G. A Educação no Maranhão. Brasília: UNICEF,MEC/ Fundescola, Banco Mundial/UNDIME, 1999.

ROSAR, M. de F.F. Globalização e descentralização: o processo de desconstrução do sistema educacional brasileiro pela via da municipalização. Campinas, UNICAMP/ Faculdade de Educação. Tese de Doutoramento, 1995.

ROSAR, M. de F.F. e SOUSA, M. S. de. Aspectos da municipalização do ENSINO no Maranhão e seus efeitos contraditórios no funcionamento da rede. Trabalho Apresentado na $22^{a}$ Reunião Anual da ANPED. Caxambu,1999.

SANTOS, E.C.M. A família no processo de inclusão do aluno portador de deficiência mental no ensino regular. Monografia curso de especialização em Educação Especial. Universidade Federal do Maranhão, 2001.
SÃO LUÍS. Secretaria Municipal de Educação. Secretaria Adjunta de Ensino. Coordenação de Educação Especial. Proposta de Reestruturação, Implantação e Implementação dos Serviços e Programas de Educação Especial na Rede Municipal de Ensino. São Luís, 2002a.

SÃO LUÍS. Secretaria Municipal de Educação. Serviços e Programas da Educação Especial. São Luís, 2002b. (mimeo).

SOUSA, M.S. de; ABREU, M.da G.R. A Execução do projeto nordeste no Estado do Maranhão - primeiras aproximações. Trabalho Apresentado na $22^{\text {a }}$ Reunião Anual da ANPED. Caxambu, 1999. 